\title{
Analysis of lysosomal membrane proteins exposed to melanin in HeLa cells
}

\author{
Seung Hyuck Bang ${ }^{1}$, Dong Jun Park ${ }^{1}$, Yang-Hoon $\mathrm{Kim}^{2}$, Jiho Min ${ }^{1}$ \\ ${ }^{1}$ Department of Bioprocess Engineering, Chonbuk National University, Jeonju; ${ }^{2}$ Department of Microbiology, Chungbuk \\ National University, Cheongju, Korea
}

\begin{abstract}
Objectives There have been developed to use targeting ability for antimicrobial, anticancerous, gene therapy and cosmetics through analysis of various membrane proteins isolated from cell organelles.

Methods It was examined about the lysosomal membrane protein extracted from lysosome isolated from HeLa cell treated by 100 ppm melanin for 24 hours in order to find associated with targeting ability to melanin using by 2 -dimensional electrophoresis.

Results The result showed 14 up-regulated (1.5-fold) and 13 down-regulated (2.0-fold) spots in relation to melanin exposure.

Conclusions It has been found that lysosomal membrane proteins are associated with melanin to decolorize and quantity through cellular activation of lysosome.
\end{abstract}

Keywords Lysosome, Lysosomal membrane proteins, HeLa cell, Melanin, 2-Dimensional electrophoresis

\author{
Correspondence: Jiho Min \\ 567 Baekje-daero, Deokjin-gu, Jeonju \\ 54896 , Korea \\ Tel: $+82-63-270-2436$ \\ Fax: +82-63-270-2306 \\ E-mail:jihomin@jbnu.ac.kr \\ Received: March 23, 2016 \\ Accepted: April 25, 2016 \\ Published: May 4, 2016 \\ This article is available from: http://e-eht.org/
}

\section{Introduction}

Melanin is a group of natural pigment striking dark color found in organisms like human and animal to protect their skins from ultraviolet (UV) radiation of sun. Melanin is generated by the oxidation of the amino acid tyrosine and considered tissues as melanocytes. Generally, melanin is classified into three types eumelanin, pheomelanin, and neuromelanin. The representative melanin is common eumelanin which shown brown and black color. However, if it is too much UV radiation exposure to skin, it will be made to cover with freckles and even may be lead to skin cancer [1]. In addition, nowadays, there is a trend that people want bright skin from dark skin.

Until now, in order to inhibit to generate melanin in skin, most of the research has been studied through interfering with melanin synthesis by inhibiting the tyrosinase [2-4]. In other words, previous studies were designed to methods for treating the melanin that has already been generated. Otherwise, some researchers tried to remove, degradation or treatment directly melanin using by extraction $[5,6]$ extracted from plant or enzymes $[7,8]$ isolated from cell organelles or themselves [9] after generating it. Proteomic analysis is important skill to find and identify unknown proteins.

Lysosome is a membrane-bound cell organelle having 50 to 60 hydrolytic enzymes associated with antimicrobial $[10,11]$, anticancerous [12] and genetic diseases [13]. So, some researchers who are believed to participate in several functions have conducted a study with respect to treat melanin using by enzymes in lysosome related organelles [14]. The lysosome is able to extract hen's egg white [7] and all of eukaryotes like Saccharomyces cerevisiae [14] and HeLa cells [8]. In previous studies, it was conducted research on lysosomal enzyme's function.

In this study, we want to know how the lysosome react the melanin. Therefore, it was tried to analysis lysosomal membrane protein isolated from lysosome extracted from activated HeLa cell directly by 2 -dimensional electrophoresis $(2 \mathrm{DE})$ assay. If the lysosomal membrane proteins are associated with treatment of melanin directly, they will be identified and the revealed proteins play important roles to use as a prescription, medical therapy and cosmetics to protect UV radiation. 


\section{Materials and Methods}

\section{Cell Cultures and Treatment}

HeLa cells were cultured in Dulbecco's modified Eagle's medium which added $5 \%$ newborn calf serum, $1 \%$ penicillin streptomycin at $37^{\circ} \mathrm{C}$ with medium under $5 \%$ carbon dioxide. All of mixtures were exchanged for every two days, and was washed using Dulbecco's phosphate-buffered saline (DPBS; Gibco, Grnad Island, NY, USA). A 100 ppm melanin was treated when the cells were grown about $70 \%$.

The melanin reagent was purchased from Sigma -Aldrich (St. Louis, MO, USA) and it was dissolved in $0.1 \mathrm{M}$ sodium phosphate buffer ( $\mathrm{pH}$ 7.0) to make melanin solution. After that HeLa cells were grown to $70 \%$, they were exposed $100 \mathrm{ppm}$ of melanin solution.

\section{Cell Toxicity Test of HeLa Cells}

Harvested cells were separated equivalent amount of them by calculation. When they grow up on the dishes, $100 \mathrm{ppm}$ of melanin treated on $0,6,12,24$, and 48 hours. Each dish was tested toxicity by 3-(4,5-dimethylthiazol-2-yl)-2,5-diphenyltetrazolium bromide (MTT) assay [8]. The colorimetric MTT metabolic activity assay is applied to determine whether melanin is able to kill cells. HeLa cells $\left(10^{4}\right.$ cells/well) were grown on a 96well plate at $37^{\circ} \mathrm{C}$. During exposing melanin on different time, the supernatant was discarded before washing cells by DPBS. After that, $20 \mu \mathrm{L}$ of MTT solution ( $5 \mathrm{mg} / \mathrm{mL}$ in DPBS) and $100 \mu \mathrm{L}$ of medium were supplemented. The plate was then incubated for four hours. Finally, $100 \mu \mathrm{L}$ dimethyl sulfoxide (Sigma-Aldrich) was added and the fluorescence signal was measured through enzyme-linked immunosorbent assay reader (Thermo Elctron, Waltham, MA, USA).

\section{Isolation of Whole Lysosomal Membrane Proteins}

To extract whole lysosomal membrane proteins in lysosomes, it was isolated lysosomes isolated lysosomes from HeLa cells beforehand. They were rinsed twice with phosphate-buffered saline, and treated with a lysis buffer $(20 \mathrm{mM}$ Tris- $\mathrm{HCl}$ $\mathrm{pH}=7.4,1 \mathrm{mM}$ EDTA, pH 8.8, 1 mM EGTA [Sigma-Aldrich] $\mathrm{pH}=8.5,1 \% \mathrm{v} / \mathrm{v}$ Triton X-100 [Daejung Chemicals \& Metals Co., Siheung, Korea]), protease inhibitor cocktail (PIC, SigmaAldrich), and phenyl methane sulfonyl fluoride (PMSF, Roche, Indianapolis, IN, USA) with ratio 100:1:1 and then vigorous agitation on a vortex mixer and kept in ice for 10 minutes. After incubation on ice, the lysates were centrifuged at $500 \mathrm{rpm}, 4^{\circ} \mathrm{C}$ for five minutes. The supernatant moved to another tube and centrifuged at $20000 \times \mathrm{g}, 4^{\circ} \mathrm{C}$ for 30 minutes. Next, lysis buffer mixed with white pellet including PIC and PMSF. Followed same vortex mixer and cooling in ice for 10 minutes. And that mixture incubated in ice for 30 minutes to react with lysosome and lysis buffer. After that the lysates were centrifuged at 13000 $\mathrm{rpm}, 4^{\circ} \mathrm{C}, 10$ minutes. The lysosomal membrane proteins were contained in the pellet. The protein concentration was determined using a Bradford assay with bovine serum albumin as the standard. The pellets were stored at $-70^{\circ} \mathrm{C}$ until analyzed by 2-dimensional gel electrophoresis.

\section{Two-dimensional Polyacrylamide Gel Electrophoresis}

Before beginning 2DE assay, whole lysosomal membrane proteins isolated from lysosome ( $20 \mu \mathrm{g}$ for each sample) in HeLa cells were resoluble into a rehydration buffer containing $350 \mu \mathrm{L}$ solution ( $7 \mathrm{M}$ urea, $2 \mathrm{M}$ thiourea, $0.5 \% \mathrm{v} / \mathrm{v}$ Triton X-100, 1\% bromophenol blue [Sigma-Aldrich], $35 \mu \mathrm{L} 1 \mathrm{M}$ dithiothreitol [Duchefa Biochemie, Haarlem, Netherlands], and 1.75 $\mu \mathrm{L}$ IPG buffer [GE Healthcare Bio-Sciences, Uppsala, Sweden]) and then the mixture put onto immobiline DryStrip $18 \mathrm{~cm}, \mathrm{pH} 4-7$, linear type (GE Healthcare Bio-Sciences, Uppasala, Sweden). A $2.5 \mathrm{~mL}$ mineral oil (Bio-Rad, Hercules, CA, USA) was added to cover onto the strip. The rehydration conditions were maintained at $50 \mathrm{mV}$ for 12 hours at $20^{\circ} \mathrm{C}$ using a protein isoelectric focusing (IEF cell, Bio-Rad). After rehydration step, paper wicks were inserted between the IPG strip and each strip holder electrode just before isoelectric focusing to adsorb excess water. The isoelectric focusing step was carried out at $20^{\circ} \mathrm{C}$ at $500 \mathrm{~V}(2$ hours), $1000 \mathrm{~V}$ (30 minutes), $2000 \mathrm{~V}$ (30 minutes), 4000 (30 minutes), 8000 (until $70000 \mathrm{~V}$ ), and $500 \mathrm{~V}$ (15 minutes). The strips were stored at $-70^{\circ} \mathrm{C}$ until running sodium dodecyl sulfate poly acrylamide gel electrophoresis (SDS-PAGE). Before performing SDS-PAGE, each isoelectric focusing strip was equilibrated for 15 minutes by until $4 \mathrm{~mL}$ a solution ( $2 \%$ SDS, $50 \mathrm{mM}$ Tris-HCl pH 8.8, 6 M urea, 30\% [v/v] glycerol [Samchun, Pyeongtaek, Korea] $0.5 \%$ bromophenol blue, and $100 \mathrm{mg}$ iodoacetamide [Sigma-Aldrich]). In sodium dodecyl sulfate poly acrylamide gel electrophoresis, the isoelectric focusing strip was loaded onto the $12.5 \%$ SDS-PAGE gel $(16.8 \mathrm{~mL} 30 \%$ bis/acrylamide (Bio-Rad), $10 \mathrm{~mL}$ of $1.5 \mathrm{M}$ Tris- $\mathrm{HCl} \mathrm{pH} \mathrm{8.8,} 13 \mathrm{~mL}$ distilled water (DW), $800 \mu \mathrm{L}$ of $10 \%$ SDS (Sigma-Aldrich), 800 $\mu \mathrm{L}$ of $10 \%$ ammonium persulfate (Sigma-Aldrich), $80 \mu \mathrm{L}$ tetramethylethylenediamine (Sigma-Aldrich). Then, approximately $3 \mathrm{~mL}$ sealing gel solution ( $0.5 \%$ agarose, $0.2 \%$ bromophenol blue) was added onto the surface of the isoelectric focusing strip. The SDS-PAGE separation was performed at $200 \mathrm{mV}, 400 \mathrm{~mA}$ for six hours at room temperature. Then, IEF gels were fixed with fixing buffer (50\% methanol, $12 \%$ acetic acid, $38 \%$ DW, and $0.00053 \%$ formaldehyde) for at least 2 hours. 


\section{Sillver Staining}

After fixing, isoelectric focusing gels were washed three times with $50 \%$ ethanol for 20 minutes. Then, gels were shaking in the sensitizing solution $\left(0.2 \mathrm{~g} / \mathrm{L}, \mathrm{Na}_{2} \mathrm{~S}_{2} \mathrm{O}_{3}\right)$ for 75 seconds. Nest, the gels were washed three times with DW by shaking at $100 \mathrm{rpm}$ for 20 seconds prior to react with $2 \mathrm{~g} / \mathrm{L} \mathrm{AgNO}_{3}$ (Junsei Chemical, Tokyo, Japan) solution during 30 minutes. After that, the stained gels were washed two times with DW before developed in a developing solution $\left(60 \mathrm{~g} / \mathrm{L} \mathrm{Na}_{3} \mathrm{CO}_{3}, 20 \mathrm{~mL}\right.$ $0.20 \mathrm{~g} / \mathrm{L} \mathrm{Na}_{2} \mathrm{~S}_{2} \mathrm{O}_{3}, 0.00053 \%$ formaldehyde [Sigma-Aldrich]). Usually, it took about five to nine minutes to display all spots on the gel. The developing process was stopped by transferring the gels into the stopping solution (50\% methanol, $12 \%$ acetic, $38 \%$ DW) and shaking at $110 \mathrm{rpm}$ for at least two hours.

\section{Spot Analysis and Data Analysis}

All stained gels were scanned to TIF files with a resolution of $300 \mathrm{dpi}$. The gel images then were cropped to the gel size using Adobe Photoshop CS5 (12.0 version $\times 64$ bit, Adobe System Inc., San Jose, CA. USA). Triplicate gels of those used to visual-

Table 1. Lists of the different expressed whole lysosomal membrane proteins in HeLa cells in response to melanin with 100 ppm

\begin{tabular}{|c|c|c|}
\hline \multirow{2}{*}{ No. of reference spot } & \multicolumn{2}{|c|}{ Fold change $^{1}$} \\
\hline & Lysosomal membrane & Control \\
\hline 253 & 3.90 & 1 \\
\hline 396 & 3.48 & 1 \\
\hline 490 & 2.70 & 1 \\
\hline 381 & 2.34 & 1 \\
\hline 370 & 2.23 & 1 \\
\hline 548 & 1.90 & 1 \\
\hline 556 & 1.83 & 1 \\
\hline 717 & 1.80 & 1 \\
\hline 474 & 1.74 & 1 \\
\hline 407 & 1.70 & 1 \\
\hline 175 & 1.67 & 1 \\
\hline 503 & 1.64 & 1 \\
\hline 82 & 1.53 & 1 \\
\hline 391 & 1.54 & 1 \\
\hline 124 & -2.04 & 1 \\
\hline 294 & -2.12 & 1 \\
\hline 501 & -2.27 & 1 \\
\hline 553 & -2.27 & 1 \\
\hline 632 & -2.30 & 1 \\
\hline 710 & -2.34 & 1 \\
\hline 242 & -2.35 & 1 \\
\hline 405 & -2.45 & 1 \\
\hline 185 & -2.53 & 1 \\
\hline 190 & -3.59 & 1 \\
\hline 217 & -3.88 & 1 \\
\hline 240 & -6.21 & 1 \\
\hline
\end{tabular}

${ }^{1}$ Fold change means that expression spots were compared with the control value. ize proteins by silver staining were scanned. The images were evaluated by using Progenesis PG200 version 2006 (Nonlinear Technology, Newcastle upon Tyne, UK) such that all major spots and all changing spots were evaluated the volume of a spot with total volume of all spots in the gels.

\section{Results}

\section{Proteomic Analysis of Whole Lysosomal Membrane} Proteins Extracted from Hela Cells Treated by Melanin

The method of to identify proteins qualitatively, there was used for proteomic analysis using by $2 \mathrm{DE}$ assay. It was examined about whole lysosomal membrane proteins extracted from HeLa cells reacted to treatment melanin by $2 \mathrm{DE}$ assay. From the proteomic analysis, the reference spots were numbered by Progenesis software, and fold change means that expression spots were compared with the control value. Lysosomal membrane proteins extracted from lysosomes in HeLa cells not treated with anything were compared with lysosomal membrane proteins treated by melanin. Lysosomal membrane proteins extracted from in HeLa cells for proteomic analysis were separated by a $\mathrm{pH}$ gradient ranging from 4 to 7 and molecular weight. The separated lysosomal membrane protein spots were profiled after silver staining to distinguish the increased or decreased proteins with control. All of data indicated lysosomal membrane proteins extracted from HeLa cells treated by commercially purchased melanin with 100 ppm for 24 hours. Normal lysosomal expression of lysosomal membrane proteins in Hela cells and were analyzed using by Progenesis PG200 software. Based on 2DE gel results, we found a lot of increased and decreased spots compared with control gel. Spots were filtered out that the levels of expressed proteins were different for each spot by at least increasing 1.5 and decreasing 2.0 fold, respectively (Table 1 ). The 14 spots of up-regulated spots (blue color) over 1.5 fold change and 13 spots of down-regulated spots (red color) down 2.0 fold than control spot change were distinguished (Figure 1). Herein, the up-regulated spots mean that the lysosome membrane proteins react more actively to access to the melanin on the contrary, down-regulated spots do not did. We observed on the basis of results that the differentially expressed proteins were activated by melanin in lysosomes and those lysosomal membrane proteins are possibly associated with quantity of used melanin. For that reason, we tried to investigate the lysosomal membrane proteins reacted to melanin by $2 \mathrm{DE}$ assay and found up-regulated 14 spots and 13 down-regulated spot in Figure 1. To identify unknown proteins, a lot of researchers used a method which has come close to reveal them through $2 \mathrm{DE}$ assay. To get better resolution spots by proteomic analysis, we used adequate total pro- 

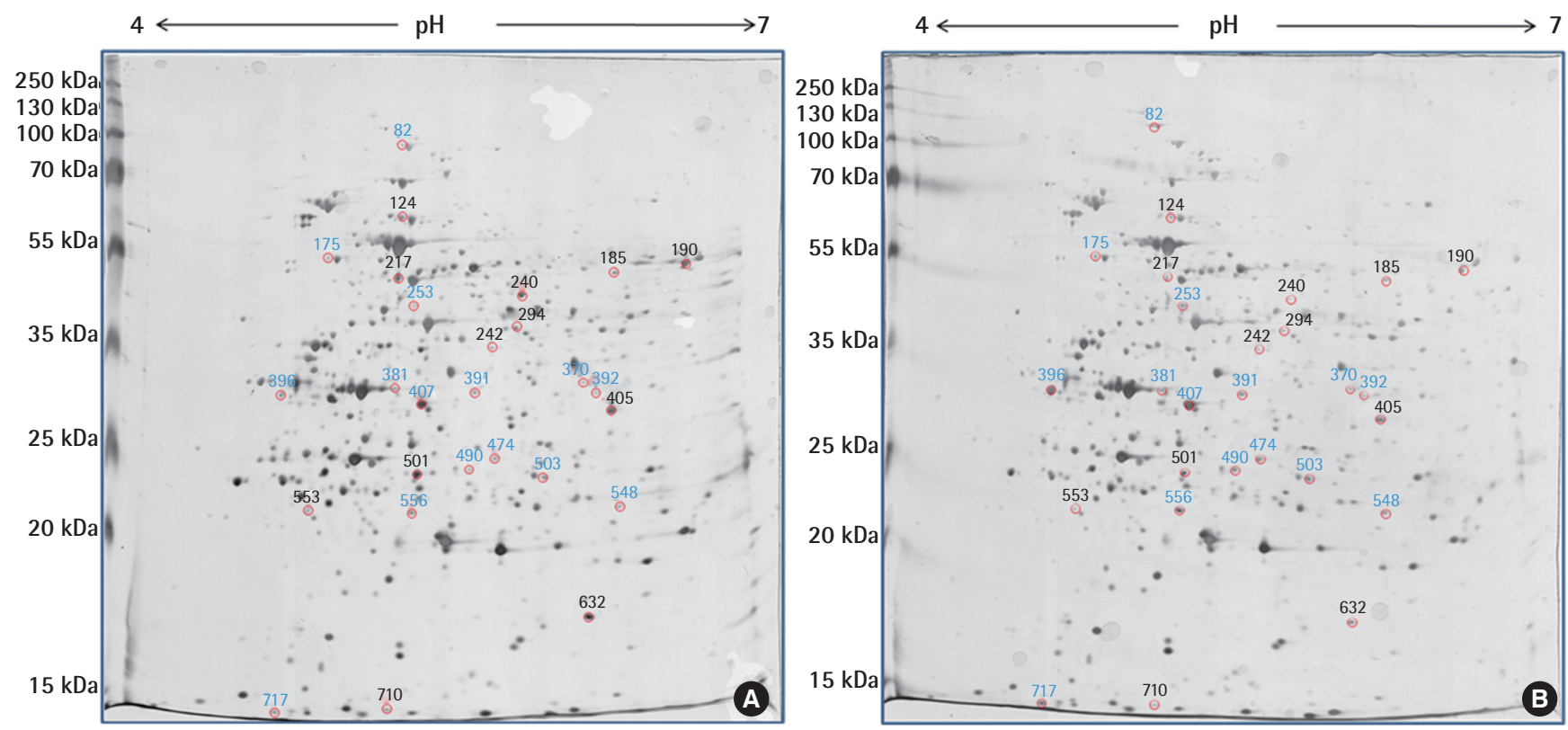

Figure 1. Whole lysosomal membrane proteins isolated from lysosome in HeLa cells treated by 100 ppm of melanin. (A) Normal lysosomal membrane proteins, (B) lysosomal membrane proteins treated by 100 ppm of melanin. Blue color means up-regulated spot and red color means down-regulated spot.

tein concentration and then we could gain high level resolution them separated. Furthermore, we can use novel biomarkers found by this research if we identify revealed spots through a matrix assisted laser desorption/ionization time-of-flight mass spectrometry.

\section{Discussion}

This study provides the proteomic analysis of lysosomal membrane proteins exposed to melanin in HeLa cells. To treat or decolorize melanin, lysosome has to draw near it. Accordingly, we would like to know how the lysosome approaches the melanin. Because the lysosomes caused to reduce melanin by lysosomal enzymes but it is not possible to contact it without lysosomal membrane having targeting function. In this experiment, we analyzed the up-regulated and down-regulated lysosomal membrane proteins after exposing $100 \mathrm{ppm}$ melanin by $2 \mathrm{DE}$. This result showed 14 up-regulated and 13 down-regulated spots. Herein, we classified up-regulated ( 1.5 fold) and down-regulated ( 2.0 fold) spots, because it is the most important thing that found up-regulated spots however down-regulated spots will be also regarded to have possibility of sufficiently used. Therefore, our results indicate that lysosomal membrane proteins possibly affect to treat or decolorize the amount of melanin exposed in lysosome due to targeting ability of them. This suggests that if the up-regulated spots use, it is possible to be as biomarkers. And then, it might be helpful in medical fields such as skin cancer and cosmetics like to decolorize skin.

\section{Acknowledgements}

This work was carried out with the support of "Cooperative Research Program for Agriculture Science \& Technology Development (project title: Development of Target-specific Antimicrobial and Neutralizing Agents for Livestock Biological Hazardous Factors, no. PJ01052701)” Rural Development Administration, Republic of Korea.

\section{Conflict of Interest}

The authors have no conflicts of interest associated with material presented in this paper

\section{ORCID}

Seung Hyuck Bang http://orcid.org/0000-0002-9023-6812

Dong Jun Park http://orcid.org/0000-0002-4209-0302

Yang-Hoon Kim http://orcid.org/0000-0002-3406-4868

Jiho Min http://orcid.org/0000-0001-6025-7746

\section{References}

1. Kricker A, Armstrong BK, English DR. Sun exposure and non-melanocytic skin cancer. Cancer Causes Control 1994;5(4):367-392.

2. Halaban R, Pomerantz SH, Marshall S, Lambert DT, Lerner AB. Regulation of tyrosinase in human melanocytes grown in culture. J Cell Biol 1983;97(2):480-488. 
3. Borges CR, Roberts JC, Wilkins DG, Rollins DE. Relationship of melanin degradation products to actual melanin content: application to human hair. Anal Biochem 2001;290(1):116-125.

4. Butler MJ, Gardiner RB, Day AW. Degradation of melanin or inhibition of its synthesis: are these a significant approach as a biological control of phytopathogenic fungi? Biol Control 2005;32(2):326-336.

5. No JK, Soung DY, Kim YJ, Shim KH, Jun YS, Rhee SH, et al. Inhibition of tyrosinase by green tea components. Life Sci 1999;65(21): PL241-PL246.

6. Chan EW, Lim YY, Wong LF, Lianto FS, Wong SK, Lim KK, et al. Antioxidant and tyrosinase inhibition properties of leaves and rhizomes of ginger species. Food Chem 2008;109(3): 477-483.

7. Bang SH, Kim P, Oh SJ, Kim YH, Min J. Impact of solvent $\mathrm{pH}$ on direct immobilization of lysosome-related cell organelle extracts on TiO2 for melanin treatment. J Microbiol Biotechnol 2015;25(5): 718-722.

8. Park DJ, Sekhon SS, Ahn JY, Yoon H, Lee L, Ko JH, et al. Different expression patterns of lysosomal proteins exposed to melanin in HeLa cells. Toxicol Environ Health Sci 2015;7(5):272-276.
9. Otaki N, Seiji M. Degradation of melanosomes by lysosomes. J Invest Dermatol 1971;57(1):1-5.

10. Bang SH, Jang A, Yoon J, Kim P, Kim JS, Kim YH, et al. Evaluation of whole lysosomal enzymes directly immobilized on titanium (IV) oxide used in the development of antimicrobial agents. Enzyme Microb Technol 2011;49(3):260-265.

11. Yoon J, Park JM, Kim KJ, Kim YH, Min J. Antimicrobial activity of the cell organelles, lysosomes isolated from egg white. J Microbiol Biotechnol 2009;19(11):1364-1368.

12. Linder S, Shoshan MC. Lysosomes and endoplasmic reticulum: targets for improved, selective anticancer therapy. Drug Resist Updat 2005;8(4):199-204.

13. Futerman AH, van Meer G. The cell biology of lysosomal storage disorders. Nat Rev Mol Cell Biol 2004;5(7):554-565.

14. Yoon J, Kim YH, Ahn JY, Lee HC, Oh SJ, Chung BW, et al. Melanin reduction by peroxidase activity in lysosome-related organelle extracts from hen egg whites, HeLa cells, and Saccharomyces cerevisiae. Mol Cell Toxicol 2015;11(4):441-447. 